\title{
Comparison of Drug Withdrawal Processes in the U.S. and Other Nations
}

Hinal Patel, BS, PharmD Candidate ${ }^{1}$; Albert Wertheimer, PhD, MBA ${ }^{2}$; Qian Ding, MS, PhD ${ }^{1}$

${ }^{1}$ Ferris State University College of Pharmacy; ${ }^{2}$ College of Pharmacy, Nova Southeastern University

\section{ABSTRACT}

Medications have been withdrawn from as early as the 1900's in several countries due to a variety of reasons. Most drugs have been withdrawn due to safety, efficacy, manufacturing issues, or the toxicities they address. While safety and efficacy of each new drug is taken into account, so is the process of drug withdrawal. Worldwide each country has its own medical agency which have different approaches on drug discovery and method of removal from the market. This removal process is simpler in several nations while more prolonged in others. Nevertheless, we still don't know an effective method of drug removal from the market and therefore that is the focus of this paper.

This paper explores the drug withdrawal process in several countries due to hepatic and cardiovascular toxicities using the WITHDRAWN database. It also summarizes and compares the drug removal processes in the U.S., Australia, UK, EU, and Canada. Consequently, there was no data or evidence that supported one country more favorable or rapid than the other. However, based on the results from drug withdrawal processes, it appeared the U.S., UK, and EU were most comparable. Meanwhile, Australia appeared to have the lengthiest process.

Keywords: Drug withdrawal, drug recall, recall procedure, adverse drug reactions, drug toxicity

\section{BACKGROUND}

The Food and Drug Administration (FDA) in the United States (U.S.) is responsible for ensuring the safety of drugs and other medical or cosmetic products marketed throughout the nation. In the U.S. many major drug product recalls led to the implementation of several acts created by the FDA. ${ }^{1}$ One of the most dangerous recalls affecting many countries happened in the early 1960's. Thalidomide became a popular sedative manufactured in 1954 by a German pharmaceutical company named Chemie-Grunenthal. ${ }^{2}$ It was used by many females to treat morning sickness throughout pregnancy. This drug was withdrawn in the early 1960's after finding out it caused teratogenicity in around 10,000 babies which led to malformation of internal organs. ${ }^{1}$ Thalidomide, not approved by the FDA in the U.S., was removed from the market in Europe and Canada in the early 1960 's. $^{3}$ This recall led to additional drug approval procedures and pushed Congress to release the 'Kefauver Amendments' to the Food, Drug, and Cosmetic Act in 1962. ${ }^{1}$ The thalidomide tragedy and many other tragic toxicities in the early 1900s caused the FDA and Congress to enact strict pharmaceutical standards for public health safety and ensure efficacy.

In recent years, many drugs have been withdrawn from the market by the FDA because of safety and efficacy concerns, adverse drug reactions, and consumer complaints. ${ }^{4}$ The FDA classifies a drug recall different from a drug withdrawal. A recall focuses on removing a product from the market perhaps due to a violation of the law or health and safety issues. ${ }^{4}$ Whereas a

Corresponding Author: Hinal Patel, BS, PharmD Candidate Ferris State University College of Pharmacy

Email: patelh21@ferris.edu drug withdrawal removes the substance from the market and the FDA would need to approve the drug once again. ${ }^{4}$ Withdrawals occur when the FDA decides that the public is at a greater risk from consuming the product. ${ }^{4} A$ drug recall is one of the surest ways the FDA can protect the public from a dangerous substance. ${ }^{5}$

There have been hundreds of drugs withdrawn worldwide primarily due to adverse drug reactions and severe toxicities. ${ }^{6}$ According to a recent study, there have been 462 medications withdrawn from the market worldwide between the years of 1953 and 2013. ${ }^{6}$ Most of these medications were found to be withdrawn due to severe drug reactions and hepatotoxicity. ${ }^{6}$ According to the results of the study, only $9.34 \%$ of the 462 identified medications were withdrawn worldwide and about $39 \%$ were withdrawn in solely one country. ${ }^{6}$ It was found that most of these drugs were withdrawn in North America, Europe, Asia, and Australia. The study concluded that we need a better system and central database to communicate withdrawn medications worldwide. ${ }^{6}$ Better coordination among drug enforcement agencies would account for better safety measures taken to decrease the risk of adverse reactions to the public.

As new medications are introduced into the market each year, it is important to learn about these adverse drug reactions and potential toxicities to prevent problems in the future. In order to assess which drugs were withdrawn from the market in each different country, a central database listing withdrawn and discontinued drugs was created. ${ }^{7}$ The database is called 'WITHDRAWN' which comprises over 500 medicinal products that were withdrawn or discontinued from the market in different countries worldwide. ${ }^{7}$ The database is comprised of about 270 drugs that were withdrawn due to safety concerns and approximately 308 that were removed due to uncertain 
reasons. ${ }^{7}$ However, in cases where the drug was withdrawn due to toxicities, the reason for withdrawal was provided in the database by a source. ${ }^{7}$ A particular focus of the database was on toxicities that were identified because of frequent adverse effects. ${ }^{7}$ There were approximately 14 categories of toxicities that were found. ${ }^{7}$ The study identified hepatic toxicity and cardiotoxicity as the major reasons for drug withdrawals. ${ }^{7}$ In the database, $21 \%$ of the drugs were withdrawn due to hepatic toxicity and $6 \%$ of drugs were withdrawn due to cardiovascular toxicity. ${ }^{7}$ The other 12 toxicity types had a drug withdrawal percentage of $11 \%$ or less. The study indicated that this database will be updated yearly as drugs continue to be withdrawn from the market in various countries. ${ }^{7}$

As the population on our planet continues to increase, so do the number of medications that we rely on to treat symptoms and improve the overall quality of life. Drug discovery takes several years as it approaches clinical trials through target validation. ${ }^{8}$ While safety and efficacy of each new drug is taken into account, so is the process of drug withdrawal. This removal process is simpler in several nations while more prolonged in others. This report will focus on the policies of drug withdrawals worldwide and how different drug withdrawal processes attribute to similar drugs being withdrawn.

\section{METHODS}

\section{Search Process}

The study process began by searching the literature on medication withdrawals in the U.S. along with different countries. It was important to find the most up to date information on the processes and medications that were withdrawn, therefore most literature found was from the 1990 's to 2019. Several search engines were used to perform the search including Google, Google Scholar, FDA Database, World Health Organization's Database, PubMed, International Pharmaceutical Abstracts, Science Direct, etc. As it was much easier finding drug withdrawal information in the United States, many other countries were a challenge and their prospective government websites were used to gather that information. To obtain information on specific withdrawal processes and medications withdrawn from the market keywords were used with the search engines mentioned above. Keywords used included "drug withdrawals", "medication withdrawals", "adverse drug reactions", "U.S. drug withdrawal process", "U.S. recalls", "drug recalls", "European drug withdrawals", "thalidomide tragedy", "most dangerous drug withdrawals" among others. Many similar combinations of keywords were used to obtain drug withdrawal information on other countries as well. These keywords helped to keep the search focused on information that was relevant to the topic of medication withdrawals.

\section{Country Selection Criteria}

Furthermore, the search for relevant articles and manuscripts continued and the drug withdrawal processes for each of the chosen countries was recorded for comparison. To find what countries should be compared to the United States, data on health care spending, country population, pharmaceutical spending, gross domestic product (GDP), and number of medical professionals were compared using the Organization for Economic Co-operation and Development (OECD) website. ${ }^{9}$ Based on these findings, the top countries that were most similar to the U.S. economy and health care system were chosen. There was no particular cut-off for a country to no longer be considered comparable to the U.S. besides the criteria mentioned above. As many countries could have been selected, those that were most similar and comparable to the United States were chosen. This data from the OECD website was documented for comparison on Microsoft Excel to observe similarities and select countries. As these countries were chosen, information on their drug withdrawal processes were found using their government websites and the search engines listed above. Following a wide range of searches, it was found that countries such as Switzerland and Norway had minimal literature on their drug withdrawal process hence were not included in this paper. Countries which had more research studies or evidence on drug market withdrawals available were selected: European Union countries, United Kingdom, Canada, and Australia.

\section{Appendix 1 Medication Selection}

Following the selection of countries similar to the U.S., the WITHDRAWN database and additional research articles played a major role in selecting withdrawn drugs shown in appendix 1. In a study that focused on drug withdrawals from the 1980's to 2009 in the U.S., it was identified that most of the withdrawals were caused from four major categories. ${ }^{10}$ These categories included hepatic toxicity, adverse drug reactions, cardiovascular toxicity, and gastrointestinal issues. ${ }^{10}$ In table 3 from the article, it showed drugs such as terfenadine, benoxaprofen, rofecoxib, valdecoxib, and troglitazone were all withdrawn due to the categories listed above as seen in appendix $1 .{ }^{10}$ After obtaining a few of these drugs with similar toxic reactions, they were searched in the WITHDRAWN database to see if other countries had also removed them from the market. As predicted, these drugs were also withdrawn in several other countries. All the drugs in appendix 1 were withdrawn in many different countries in addition to the U.S. This gave an idea of which countries withdrew drugs similar to the U.S. After the selection of medications in this manner, the WITHDRAWN database also showed that the largest categories of drug withdrawal were hepatic and cardiovascular toxicity, therefore those categories were focused on in this report. Further research was done using the search engines mentioned above using keywords such as hepatotoxicity and cardiovascular toxicity in medications. This search was conducted to find why these two categories had such a high rate of drug withdrawal. 


\section{RESULTS}

The United States Food and Drug Administration (US-FDA) is the responsible agency for regulating many products including prescription and non-prescription drugs. ${ }^{11}$ The FDA works with the Center for Disease Control (CDC) and both entities are in charge of promoting and ensuring the health of the population. The FDA regulates food and drug products to be released in the market and also withdraws substances to protect the public. The FDA has strict following measures on the drug approval process along with the drug withdrawal process. The drug approval process is lengthy which comprises of many phases of clinical trials and applications before a drug can be brought to the market. ${ }^{8}$
USA

In the U.S., most drugs are removed from the market by a manufacturer request to withdraw the product or an FDA request due to public health hazards. ${ }^{12}$ The FDA works with the manufacturer and both entities agree that the drug product needs to be removed. ${ }^{12}$ The FDA becomes aware of an adverse effect caused by a drug product through manufacturer complaints. Manufacturers get reports from various sources such as hospitals, pharmacies, healthcare practitioners, and consumers. Depending on severity of the harmful substance, the FDA classifies recalls in three different categories illustrated in Figure $1 .^{4}$

\section{Figure 1}

\begin{tabular}{|l|l|l|}
\hline \multicolumn{1}{|c|}{ Class 1 } & \multicolumn{1}{|c|}{ Class 2 } & \multicolumn{1}{c|}{ Class 3 } \\
\hline $\begin{array}{l}\text { The substance is a severe health } \\
\text { hazard to the public. May result in } \\
\text { severe adverse reactions or even } \\
\text { death. }\end{array}$ & $\begin{array}{l}\text { The substance is a possible health } \\
\text { hazard to the public. Results in } \\
\text { potential adverse reactions and not } \\
\text { likely to cause death. }\end{array}$ & $\begin{array}{l}\text { The substance is not a significant } \\
\text { health hazard to the public. Not } \\
\text { likely to cause any severe health } \\
\text { outcomes. }\end{array}$ \\
\hline
\end{tabular}

Following legal regulations and documentation by the FDA and distributors, the FDA issues a warning to alert the public of a potential health hazard caused by the product being withdrawn. ${ }^{12}$ Once this occurs and all the information is released through the press, television news channels, hospitals, pharmacies and many more, the distributor and FDA conduct effectiveness checks. ${ }^{12}$ This effectiveness check assures that the correct individuals involved in the withdrawal and consignees are aware of the situation and proper protocols have taken place. ${ }^{12}$ The drug withdrawal is further communicated to the public by appropriate measures of telegrams, mail, emails, and phone calls. Recall status reports are made every two and four weeks to assess how many individuals responded to the effectiveness checks to conclude the recall. ${ }^{12}$ Finally, once the FDA is aware that all consignees, the public, health industries, and healthcare workers are alerted of the recall and the product is disposed of correctly from all public places, the recall is terminated. ${ }^{12} \mathrm{~A}$ brief timeline of the events discussed are shown in Figure $2 .^{12}$

Figure 2

\section{U.S. Drug Withdrawal Process}

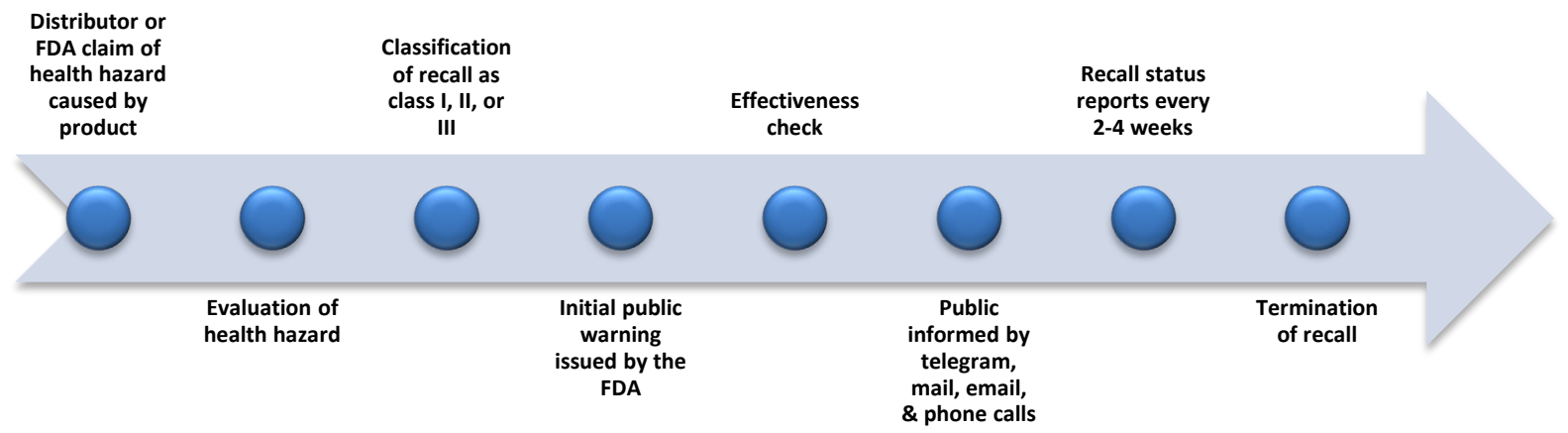


European Union

The European Union (EU) consists of 27 countries, it is home to about twice the number of people in the U.S. The agency that is in charge of public health in the EU is called the European Medicine Agency (EMA). ${ }^{12}$ The EU issues a recall based on consumer complaints. They have a set procedure on how to approach the situation whenever consumer complaints happen due to a product. ${ }^{12}$ The EMA assesses the complaints based on quality or manufacturing issues or other concerns and then uses Corrective and Preventative Actions (CAPAs) to appropriately make a decision. ${ }^{12}$ CAPAs include finding the root of the cause for the quality defect. ${ }^{12}$ They investigate the issues and make a decision for quality defects and report of any noncompliance that could have occured. ${ }^{12}$ The EMA then classifies this defect as a class 1,2 , or 3 recall. Class 1 entails of a severe health hazard to the public and class 3 accounts for a product that isn't likely to cause major adverse effects. The specific batch of that defected product is documented and the records are available for the manufacturers and consumers who may have purchased the product. ${ }^{12}$ Other competent authorities and member states are aware and alerted of the recall, however in the case that the recall is severely hazardous to public health, other serious and rapid actions are taken to reduce potential injuries. ${ }^{12}$ The EMA records the procedure and status of each recall until a final statement is issued. ${ }^{12}$ All of the defected products or batches are withdrawn from the market and the Commission or European council informs the Member States. ${ }^{12}$ This information that the Member States obtain is then communicated to the public and the Commission ensures the correct information is given. ${ }^{12}$

The withdrawal procedure in the EU is appears to be more rapid, however the public gets notified of the recall in the last step. Depending on the severeness of the recall, this may be tremendously hazardous to the public. The USA and EU comparative analysis research article shows that the U.S. has 2,028 products recalled while the EU only has 15 in $2015 .^{12}$ Similar products recall trends between the U.S. and the EU were found in 2014-2016. ${ }^{12}$ This may implicate why the EU does not inform the public in the initial stages of a recall, as they have very few recalls yearly.

\section{Australia}

In Australia, the Therapeutic Goods Administration (TGA) is the agency that mandates drug and other product recalls for the country. ${ }^{13}$ The TGA holds responsibility of drug regulation for the country. In Australia, the TGA breaks down recalls based on the types, classes and levels of recall. There are 4 different types which include immediate recalls, other recalls, non-recall actions, and product tampering. ${ }^{13}$ Based on the type of recall, steps are provided on the government website for a specific procedure to follow. This recall procedure is provided in a flowchart manner on the government website and states which officials and other responsible parties should be contacted immediately. ${ }^{13}$

Whether the product recall is for biologicals, pharmaceuticals, or product tampering, the first step is immediate recall. ${ }^{13}$ This is for drugs or products that pose a great risk to the public. In this stage, the Australian Recall Coordinator along with consumers are initially alerted about the potential risks caused from the product. ${ }^{13}$ After this step, the rest of the steps are the same for all other recalls. Step 2 includes collecting the appropriate information for product distribution and stock status. ${ }^{13}$ This comprises of the description of the issue caused by the product, contact information of the individuals responsible for the recall (notifiers), description and report of the product which includes batch numbers or pack sizes. ${ }^{13}$ Step 3 entails of conducting a risk analysis which helps decide the type of recall which is found in step $4 .^{13}$

In step 4, the notifiers decide the type of recall, class of recall, and level of recall. ${ }^{13}$ Similar to the U.S. the class of recall defines the risks associated with the recall products, in which Class 1 includes the product to have a severe health risk while Class 3 means a lower risk caused by the product. ${ }^{13}$ The levels of recall decide who has been in contact with the product and which of the following categories are affected: wholesale, hospital, retail, and consumer. ${ }^{13}$ Step 5 entails developing an effective recall strategy to properly recall the harmful products and prepare a plan. ${ }^{13}$ Step 6 involves contacting the TGA and planning a communication strategy to notify everyone involved with the recall. ${ }^{13}$ This step is where consumers and media receive another notice about the recall to further alert the public about the situation. Step 7 and 8 comprise of finally submitting the recall information and having TGA assess the recall. ${ }^{13}$ Steps 9 to 11 consist of executing the recall and getting consumer feedback, recording status reports on the recall, discussing any further preventative strategies, and having a final check by the TGA to decide of any further actions are necessary. ${ }^{13}$ Similar to the EU, the TGA also uses CAPAs to prevent the reoccurrence of the situation. ${ }^{13}$

As stated above, the Australian recall process, containing 11 steps, appears a lot lengthier than most other nations. Also, although the TGA has a written procedure on how to implement a recall, every recall can be slightly different depending on the type of recall and how the manufacturers would like to convey the message. Figure 3 summarizes each step in the Australian product recall procedure. ${ }^{13}$ 
Figure 3

Australian Drug Product Withdrawal Process

- Immediate recall procedure

- Collection of product information

- Risk analysis of product

- Classifying the recall

- Devoloping a recall plan

- Developing a communication plan

- Submitting the recall strategy

- Recall assessment by the TGA

- Executing the recall

- Reporting status reports on recall

- Reviewing the recall

United Kingdom of Great Britain and Northern Ireland

The United Kingdom has its own regulatory authority called the Medicines and Healthcare Products Regulatory Agency (MHRA). ${ }^{14}$ The Defective Medicines Report Centre (DMRC) oversees the inspection and enforcement of defective medicinal products to reduce health hazards to the public. ${ }^{14}$ While the MHRA has legislative authority to handle a recall, the DMRC actually takes over. ${ }^{14}$ The DMRC is part of the MHRA.

The initial step in the UK drug recall process is by the patient or responsible party reporting the drug reaction to the DMRC. ${ }^{15}$ When an adverse reaction is found from a defective medicinal product, the patient or provider reports the reaction and information on the product on the electronic defect reporting form. ${ }^{15}$ In the event that the information cannot be reported online, the individual can make a verbal report. ${ }^{15}$ The DMRC may follow-up to ask for additional information on the product or what was observed. Next, an initial assessment of the defected product are done by trained healthcare professionals which is followed with a similar assessment of product by the DMRC. ${ }^{15}$ Healthcare providers may also contact the MHRA for additional advice. Furthermore, the DMRC will investigate the product and decide what batch of the product needs to be recalled, what class the recall falls under, and if the recall should be alerted to the public using an MHRA drug alert. ${ }^{15}$

The UK classification system is similar to the US where a class 1 product proposes a severe risk to the public, class 2 less of a risk, and a class 3 product is unlikely to propose a severe risk to the public. ${ }^{15}$ The MHRA will also issue class 4 drug alerts which will alert the public to use caution when using that medicinal product. ${ }^{14}$ When the decision of the recall is made, the manufacturer is responsible to also alert its customers and involved parties about the defective product. ${ }^{15}$ Additionally, healthcare professionals who supply medications are required to ensure they are not supplying this defective medication and all patients are aware of the drug recall. ${ }^{15}$ Lastly, a final followup is required by the licensed manufacturer and DMRC to ensure the proper protocols took place and all responsible parties have implemented the product recall. ${ }^{15}$

The UK drug recall appears more rapid than most other nations as it doesn't have as long of a process. However, similar to Australia, the manufacturer is primarily in charge of handling the recall and ensuring all responsible parties are aware of the recall. Additionally, in any step of the UK recall process, if any patients, healthcare professionals, or manufacturers have questions regarding reporting a recall, they may contact the DMRC or MHRA as they both work consecutively to recall the product and assess risks.

Canada

The agency in charge of drug regulation in Canada is called Health Canada. Products sold in Canada are monitored by Health Canada to ensure that they propose no health hazards or risks to the public. ${ }^{16}$ Similar to the U.S., Canada makes sure it is in compliance with the Food and Drug Act along with Food and Drug Regulations proposed by the government. ${ }^{16}$ Being in compliance with these guides help assess product recall requirements for the country. The drug recall process in Canada 
is similar to a few of the countries mentioned above such as the European Union, Australia and United Kingdom. They are similar due to the fact their responsible party in charge of the recall include manufacturers, distributors, importers, or wholesalers. ${ }^{16}$ It is their job to ensure that the proper recall requirements take place and Health Canada is informed of the drug recall.

The initial step in Canada's drug recall process is the responsible party notifying Health Canada about a potential recall taking place. ${ }^{16}$ Most manufacturers become aware of proposing a recall when they hear back from consumers, healthcare practices, or even government authorities of adverse reactions. It is the manufacturers responsibility to effectively execute a recall while following the governments regulatory requirements. ${ }^{16}$ Once Health Canada is aware of the recall, they will confirm that a proper recall procedure is taking place by the manufacturer according to the regulations. ${ }^{16}$ The recall notification to Health Canada is done through an electronic product recall form. ${ }^{16}$ It is the manufacturers duty to assess the risk of the recall by Canada's classification system as Type 1, 2, or $3 .{ }^{16}$ A classification of type 1 means that the product can cause severe harm or even death to the public whereas type 3 means the product will not be as hazardous to the public and type 2 being an intermediate risk. ${ }^{16}$

Once the recall is classified, Health Canada will investigate the product recall form and undergo any additional procedures needed to evaluate the risk the drug product causes the public. ${ }^{16}$ Following the investigation, the manufacturer is required to have a product recall strategy in place following the regulations and must provide those to Health Canada. There is a list of regulations on the Canadian government website that the manufacturer is expected to follow when providing a strategy of recall. ${ }^{16}$ Once Health Canada assesses the recall strategy and recommends any changes, the manufacturer is required to make a timeline of how to communicate the recall to the public. ${ }^{16}$ This communication timeline is overseen by Health Canada and an initial warning to the public is based on the classification type of the recall. ${ }^{16}$ The communication timeline is very closely monitored by Health Canada to ensure every individual that could have come in contact with the product recall is aware. Following proper communication methods to responsible parties and consumers, effectiveness checks and reports are done based on the type of recall to ensure the corrective actions were taken place and consignees are aware of the situation. ${ }^{16} \mathrm{~A}$ final progress report is provided to Health Canada by the manufacturer on how the recall strategy was followed through and the amount of product recovered from public places along with disposal methods. ${ }^{16}$

\section{DISCUSSION}

After reviewing the drug withdrawal processes in each of the countries stated previously, it showed that some countries such as the EU and UK had a very concise and efficacious process while others not so much. In the U.S., most of the drug withdrawal process was executed by the FDA whereas in all of the other countries the distributor or manufacturers were in charge of the recall. It is more beneficial if the health agency takes over while issuing the recall as it was seen in the U.S., it seemed to make the process more rapid. In the U.S. drug recall process, the FDA took charge and recalled the product as efficiently as possible. This eliminated the need for a manufacturer to recall a product and keep checking in with the FDA during each step. No doubt, the manufacturer and other responsible parties should be available and engaged in the recall for any additional information that may be needed. However, it appeared that when the health agency or government got involved with every step the process seemed uncomplicated. Having the health agency involved in every step also eliminates the need for the manufacturer to continue reaching out with any questions and having to wait to hear back, possibly delaying the process.

An effective way of communication was also a standard that each country follows. This is very important as the public should be alerted immediately in the case that someone continues to take the defective drug product. In the EU, UK, Australia, and Canada warning the public does not happen immediately but later on in the process. These countries first assess and investigate the situation and the specific drug product then proceed to plan for a recall strategy before warning the public of a possible recall. It is essential to immediately alert the public that a possible drug recall is in the process for a specific medication and then provide another official statement with more specific information such as batch numbers, disposal process, and when to consult a physician. This would potentially decrease health hazards caused from the drug product and physician or pharmacy visits on potential confusion about the medication.

Overall, based on the amounts of drug withdrawals every year it appears that the USFDA does an effective job removing a drug off the market whenever needed. Some countries such as the EU had fewer drug recalls within the past ten years whereas the U.S. had much more, hence the length of their drug withdrawal process may not make a significant difference as it does for the U.S. However, having two agencies involved in the process seemed to make it more complicated. Consequently, there was no data or evidence that supported one country more favorable or rapid than the other. However, based on the results from drug withdrawal processes, it appeared the U.S., UK, and EU were most comparable.

\section{CONCLUSION}

Drug withdrawals continue to be a hardship that almost all countries go through. New products continue to be released to the market for the numerous amounts of health conditions that are diagnosed yearly. New health conditions and disease states are continually being discovered that require medical treatment. Hence, drug withdrawal processes in each nation will continue being updated as technology and science continue 
to evolve. With databases and online list features on government websites, obtaining information and potentially trying to update a withdrawal process seem to have become much simpler. As mentioned previously through the WITHDRAWN database, cardiac and hepatic toxicities are a major concern of drug withdrawals each year. Yet, the U.S. continues being one of the top countries to withdraw medications from the market whereas other countries do not withdraw as many medications. Although there may be monetary benefits for major companies in those countries keeping certain medications on the market, it is important to continue assessing risks that certain products may cause the public.

\section{REFERENCES}

1. Glauberman S. The Real Thalidomide Baby: The Evolution of the FDA in the Shadow of Thalidomide, 1960-1997. The Real Thalidomide Baby: The Evolution of the FDA in the Shadow of Thalidomide, 1960-1997. Published 1997. Accessed June 15, 2020. https://dash.harvard.edu/handle/1/8852132

2. Vargesson N. Thalidomide-induced teratogenesis: History and mechanisms. Birth Defects Res C Embryo Today. 2015;105(2):140-156. doi:10.1002/bdrc.21096

3. Franks ME, Macpherson GR, Figg WD. Thalidomide. The Lancet. 2004;363(9423):1802-1811. doi:10.1016/S0140-6736(04)16308-3

4. Nagaich U, Sadhna D. Drug recall: An incubus for pharmaceutical companies and most serious drug recall of history. Int J Pharm Investig. 2015;5(1):1319. doi:10.4103/2230-973X.147222

5. U.S. Food and Drug Administration. FDA's role in drug recalls. FDA. Published November 3, 2018. Accessed June 8,2020 . https://www.fda.gov/drugs/drugrecalls/fdas-role-drug-recalls

6. Onakpoya IJ, Heneghan CJ, Aronson JK. Postmarketing withdrawal of 462 medicinal products because of adverse drug reactions: a systematic review of the world literature. BMC Med. 2016;14(10):1-11. doi:10.1186/s12916-016-0553-2

7. Siramshetty VB, Nickel J, Omieczynski C, Gohlke B-O, Drwal MN, Preissner R. WITHDRAWN-a resource for withdrawn and discontinued drugs. Nucleic Acids Res. 2016;44(Database issue): D1080-D1086. doi:10.1093/nar/gkv1192

8. Lipsky MS, Sharp LK. From idea to market: the drug approval process. J Am Board Fam Pract. 2001;14(5):362-367. Accessed June 23, 2020. https://www.jabfm.org/content/14/5/362

9. Organisation for Economic Co-operation and Development (OECD). Health resources - Health spending - OECD Data. OECD. Published 2020. Accessed August 4, 2020. http://data.oecd.org/healthres/health-spending.htm
10. Qureshi ZP, Seoane-Vazquez E, Rodriguez-Monguio $R$, Stevenson KB, Szeinbach SL. Market withdrawal of new molecular entities approved in the United States from 1980 to 2009. Pharmacoepidemiology and Drug Safety. 2011; 20(7):772-777. doi:10.1002/pds.2155

11. U.S. Food \& Drug Administration. What does FDA regulate? Published August 3, 2020. Accessed August 16, 2020. https://www.fda.gov/about-fda/fdabasics/what-does-fda-regulate

12. Dharmesh B, Venkatesh MP, Kumar TMP. Pharmaceutical Product Recall in USA and EU: Comparative analysis. 2018;10(4):5.

13. Australian Government Department of Health Therapeutic Goods Administration. Uniform recall procedure for therapeutic goods. Therapeutic Goods Administration (TGA). Published December 12, 2019. Accessed June 23, 2020. https://www.tga.gov.au/recall-procedure

14. Nandhini B, Balamurlidhara V, Gulumkar AA, Sridhar $S$. Drug recall procedure in United Kingdom and Australia: a regulatory overview. International Journal of Research in Pharmaceutical Sciences. 2020;11(2):1457-1466. doi:10.26452/ijrps.v11i2.2018

15. Medicines and Healthcare Products Regulatory Agency. A guide to defective medicinal products. Published online July 5, 2003. Accessed September 3, 2020.

https://www.gov.uk/government/publications/aguide-to-defective-medicinal-products

16. Canada H. Drug and natural health products recall guide. Published July 23, 2020. Accessed September 6, 2020. https://www.canada.ca/en/healthcanada/services/drugs-health-products/complianceenforcement/recalls/guidance-drug-natural-healthproducts/document.html\#a2.1.4

Acknowledgements: Thank you to American Association of Colleges of Pharmacy (AACP) for giving me the opportunity to participate in the Social and Administrative Sciences (SAS) Section Summer Research Exchange Mentorship Program. Also, a special thank you to Alison Konieczny the Health Sciences Librarian at Ferris State University in aiding me in locating efficient search engines for reference materials.

Conflict of Interest: We declare no conflicts of interest or financial interests that the authors or members of their immediate families have in any product or service discussed in the manuscript, including grants (pending or received), employment, gifts, stock holdings or options, honoraria, consultancies, expert testimony, patents and royalties. 
Appendix 1: Cardiac/Hepatic Toxicity Drugs Withdrawn in the U.S. \& Worldwide

\begin{tabular}{|c|c|c|c|c|}
\hline Drug & $\begin{array}{l}\text { Date } \\
\text { Effective }\end{array}$ & Treatment & Reason for Withdrawal & Countries it was Recalled In \\
\hline Benoxaprofen & 1982 & Arthritis & Hepatic injury & Worldwide \\
\hline Benzarone & 1992 & Gout & Hepatic injury & FRA \\
\hline Bromfenac & 1998 & Eye pain, swelling & Serious liver problems & USA, SAU (Saudi Arabia) \\
\hline Cerivastatin & 2001 & Lowers cholesterol & $\begin{array}{l}\text { Damaged skeletal muscle } \\
\text { (rhabdomyolysis) }\end{array}$ & Worldwide \\
\hline Dolasetron & 2011 & Nausea and vomiting & $\begin{array}{l}\text { Sever hypotension, } \\
\text { cardiac channel block }\end{array}$ & DEU (Germany) \\
\hline Ephedra & 2004 & $\begin{array}{l}\text { Asthma, congestion, } \\
\text { fever, hypotension }\end{array}$ & $\begin{array}{l}\text { Cardiotoxicity, } \\
\text { neurotoxicity }\end{array}$ & USA \\
\hline Gatifloxacin & 2006 & Conjuctivitis & $\begin{array}{l}\text { Dysglycemia, adverse } \\
\text { reactions }\end{array}$ & USA \\
\hline Mibefradil & 1998 & $\begin{array}{l}\text { Hypertension, angina } \\
\text { pectoris }\end{array}$ & Adverse health effects & Worldwide \\
\hline $\begin{array}{l}\text { Phenylpropanola } \\
\text { mine }\end{array}$ & 2000 & Decongestant & Hemorrhagic stroke & CAN (Canada), USA \\
\hline Pirprofen & 1990 & Arthritis and pain & Fatal liver problems & Worldwide \\
\hline Rofecoxib & 2004 & $\begin{array}{l}\text { NSAID used to treat } \\
\text { pain }\end{array}$ & Heart attack/stroke & USA \\
\hline Rosiglitazone & 2010 & Type II diabetes & Heart attack & EU (European Union) \\
\hline Sitasentan & 2010 & $\begin{array}{l}\text { Pulmonary arterial } \\
\text { hypertension }\end{array}$ & Hepatic damage & DEU (Germany) \\
\hline Terfenadine & 1997 & Allergies & $\begin{array}{l}\text { Abnormal cardiac } \\
\text { arrhythmia }\end{array}$ & $\begin{array}{l}\text { ARG (Argentina), BRA (Brazil), CHL } \\
\text { (Chile), EU, ISL (Iceland), SAU, SGP } \\
\text { (Singapore) }\end{array}$ \\
\hline Trogiltazone & 2000 & Type II diabetes & Liver poisoning & $\begin{array}{l}\text { USA, GBR (Great Britain), PER (Peru), } \\
\text { DEU, CHL }\end{array}$ \\
\hline Valdecoxib & 2004 & $\begin{array}{l}\text { NSAID used to treat } \\
\text { pain }\end{array}$ & $\begin{array}{l}\text { Skin conditions, heart } \\
\text { attack/stroke }\end{array}$ & USA, EU \\
\hline
\end{tabular}

